\title{
Contraceptive failure and the progestogen-only pill: the issue of body weight
}

\author{
Julia Chandler, Kate Nash
}

\section{Case report}

In December 2008, a 33-year-old, para 2 gravida 4, Caucasian woman presented to the sexual and reproductive health (SRH) community clinic requesting termination of pregnancy (TOP). This was an unintended pregnancy and she had been taking the progestogen-only pill (POP) etynodiol diacetate $500 \mu \mathrm{g}$ (Femulen ${ }^{\circledR}$ ) one tablet a day. The original prescription from the SRH clinic was for two tablets a day, but on requesting further pills from her general practitioner (GP) she was prescribed one a day. She conceived about 3 months after the dose was reduced. She weighed $105.8 \mathrm{~kg}$ and had a body mass index (BMI) of 36 . She had no relevant past medical history and was taking fluoxetine and pericyazine but no herbal remedies. There was no history of diarrhoea or vomiting or missed pills. Transvaginal ultrasound revealed a single viable intrauterine pregnancy of about 5 weeks' gestation. She proceeded to an early medical abortion. After discussion of contraceptive options the woman preferred to resume Femulen, two tablets a day. She was followed up by her GP 3 months later and Femulen was changed to desogestrel $75 \mu \mathrm{g}\left(\right.$ Cerazette $\left.^{\circledR}\right)$. Unfortunately, 6 months after her TOP she was unintentionally pregnant again. On close questioning she reported good compliance with Cerazette. She had stopped her antidepressants and the only concurrent medication was a 1 -week course of amoxicillin 6 weeks previously. Transvaginal ultrasound revealed a viable intrauterine pregnancy of 7 weeks and 4 days' gestation. Again she proceeded to an early medical abortion. This time she opted for the etonogestrel implant (Implanon ${ }^{\circledR}$ ) post-procedure.

Thus this woman had two POP failures resulting in TOP within a 7-month period: the first when taking a traditional POP and the second when on the desogestrel-only pill. In this case report we discuss the controversy regarding POP dose and weight and explore the existing evidence.

\section{Discussion}

The Faculty of Sexual and Reproductive Health (FSRH), in their current guidance, advise that there is no evidence that the efficacy of the POP is reduced in women weighing over $70 \mathrm{~kg}$ and that the pill should be prescribed at the licensed dose of one pill per day. ${ }^{1}$ In the present case, the GP correctly followed FSRH guidance in accordance with this recommendation.

It is striking, and unfortunate, that this woman had a pill failure with the traditional POP and also the desogestrelonly pill. The traditional POP works primarily by effects on cervical mucus. It has been demonstrated that the desogestrel-only pill inhibits ovulation more effectively and this is its primary mode of action. However, the FSRH's current guidance ${ }^{1}$ states that the available study ${ }^{2}$ was not

J Fam Plann Reprod Health Care 2009; 36(3): 167-168

(Accepted 18 May 2010)

Central Family Planning Clinic, Norwich, UK Julia Chandler, MRCGP, DFSRH, General Practitioner Kate Nash, MFSRH, DRCOG, Consultant

Correspondence to: Dr Julia Chandler, Central Family Planning Clinic, Grove Road, Norwich NR1 3RH, UK.

E-mail: julia.chandler@nnuh.nhs.uk powered to detect differences in efficacy, and the failure rates of the two POPs are not proven to be significantly different. In our unit we advise two (traditional) POPs per day in women under 45 years of age who weigh more than $70 \mathrm{~kg}$, although this may not be necessary for women at low risk of pregnancy, such as those who are fully lactating. We also advise two POPs per day or the desogestrel-only pill for any woman who has had a 'true' contraceptive failure on the POP in the past. In view of the present case, the question arises of whether we can still trust the presumed, yet unproven, greater efficacy of the desogestrel-only pill. Anecdotally we know that some clinicians are advising two desogestrel-only pills a day for women heavier than $100 \mathrm{~kg}$. Clearly there is a need to weigh up the risks and benefits in each individual woman's case and for a careful, documented discussion to take place.

In examining the available literature we find that Vessey and Painter explored oral contraceptives and body weight in a large cohort study. ${ }^{3}$ They found that there was no statistical significance in the slightly higher rate of accidental pregnancies in the group on the POP weighing $82 \mathrm{~kg}$ or more. Their study did not, however, have enough power either to support the hypothesis that there was a higher failure rate in this group or disprove it.

We draw on evidence from studies undertaken in women using Norplant ${ }^{\circledR}$ or the levonorgestrel-releasing vaginal ring. ${ }^{4,5}$ With regard to Norplant, the study showed a trend of increasing pregnancy rate and weight. ${ }^{4}$ This was statistically significant for the early Norplant with the denser tubing. In Sivin's study, women weighing above $70 \mathrm{~kg}$ experienced the highest overall pregnancy rates. The results showed that the total gross cumulative pregnancy rate at 60 months was 0.2 per 100 for women weighing less than $50 \mathrm{~kg}$ in contrast to 7.6 per 100 for women over $70 \mathrm{~kg} .{ }^{4}$ Therefore, the findings of studies using Norplant suggest that a relationship between progestogen-only contraceptives and weight does exist but that studies to date using POPs have not been sufficiently large to detect this.

A World Health Organization study comprising 1005 women using the levonorgestrel-releasing vaginal ring also supports the relationship between increasing pregnancy rate and body weight. ${ }^{5}$ In this study researchers found an estimated pregnancy rate of $1.7 \%$ for women weighing $40 \mathrm{~kg}$ and $9.8 \%$ for those weighing $80 \mathrm{~kg} .5$

On the basis of this evidence, the Clinical Effectiveness Unit (CEU) advised in 2003 that pending more evidence the two-pill regime may be more appropriate in young women. ${ }^{6}$ This 2003 advice has now been superseded by the current POP guidance document ${ }^{1}$ mentioned earlier, which advises one pill per day. It is not surprising that this change in advice represents a common area of confusion in clinical practice, especially for non-specialists.

So far as the present case is concerned, after the woman's second POP failure the recommendation was a change to a long-acting reversible contraceptive (LARC) method, the most reliable option. However, if a woman wishes for a progestogen-only oral contraceptive method then the question remains should a double dose of pill be prescribed? Is a double dose less risky than an unintended pregnancy in a heavy woman? There remain a lot of unanswered questions and a lack of conclusive data. Also the studies to date tend to base their data on weight; 
however, this is not the same as BMI. A woman over 6 feet tall may well weigh more than $70 \mathrm{~kg}$. Does this make a difference? Trussell et al. ${ }^{7}$ have recently highlighted the limitations in obtaining reliable data, for example, when based on patients' self-reported pill adherence. With the growing incidence of obesity, the need for conclusive guidance becomes increasingly relevant and vital. We would suggest that in the absence of definite evidence it is safer for heavier women to take two POPs than risk an unintended pregnancy. However, we would welcome more evidence on this issue, and indeed some evidence specifically relating to Cerazette.

\section{Statements on funding and competing interests \\ Funding None identified. \\ Competing interests None identified.}

\section{Editor's note}

The FSRH Clinical Effectiveness Unit (CEU) was invited to comment on this Case Report. Their response letter is on page 181 of this issue.

\section{References}

1 Faculty of Sexual and Reproductive Healthcare Clinical
Effectiveness Unit. Progestogen-only Pills. November 2008 (Updated June 2009). http://www.fsrh.org/admin/uploads/ CEUGuidanceProgestogenOnlyPill09.pdf [Accessed 2 May 2010].

2 A double-blind study comparing the contraceptive efficacy, acceptability and safety of two progestogen-only pills containing desogestrel 75 micrograms/day or levonorgestrel 30 micrograms/day. Collaborative Study Group on the Desogestrel- containing Progestogen-only Pill. Eur $J$ Contracept Reprod Health Care 1998; 3: 169-178.

3 Vessey M, Painter R. Oral contraceptive failures and body weight: findings of a large cohort study. J Fam Plann Reprod Health Care 2001; 27: 90-91.

4 Sivin I. International experience with NORPLANT ${ }^{\circledR}$ and NORPLANT ${ }^{\circledR}-2$ contraceptives. Stud Fam Plann 1988; 19: 81-94.

5 Koetsawang S, Ji G, Krishna U, Cuadros A, Dhall GI, Wyss R, et al. Microdose intravaginal levonorgestrel contraception: a multicentre clinical trial III. The relationship between pregnancy rate and body weight. World Health Organization. Task Force on Long-Acting Systemic Agents for Fertility Regulation. Contraception 1990; 41: 143-150.

6 De Souza A, Brechin S, Penney G. The members' enquiry service: frequently asked questions. J Fam Plann Reprod Health Care 2003; 29: 160-161.

7 Trussell J, Schwarz E, Guthrie K. Obesity and oral contraceptive pill failure. Contraception 2009, 79: 334-338.

\section{NEWS ROUNDUP}

\section{Contraception in the BNF}

The Faculty of Sexual and Reproductive Healthcare's Clinical Effectiveness Committee have recently been working closely with the British National Formulary (BNF) in an effort to try and improve the consistency and standardisation of the information provided on contraception. Changes to Section 7.3 (Contraceptives) have been made that bring the BNF into line with the 2009 edition of $U K$ Medical Eligibility for Contraceptive Use (UKMEC 2009) and Faculty guidance. The twoway consultation that resulted in the recent amendments is envisaged to be an ongoing process. Hopefully Journal readers/clinicians who use the BNF will have noticed these changes.

\section{Reviewed by Shelley Mehigan, RGN}

Nurse Specialist (Contraception), Berkshire East Community Health Services, Sexual Health,

Upton Hospital, Slough, UK

\section{Decrease in the abortion rate and} major shift towards early abortion

The publication of the 2009 abortion statistics from the Department of Health reveals that the number of abortions for women resident in England and Wales was 189100 compared with 195296 in 2008, a fall of $3.2 \%$. The total figure, including those performed for non-residents, was 195743 for 2009, compared with 202158 in 2008.

The majority of abortions are performed at under 13 weeks' gestation. The latest data for 2009 show that progress continues to be made to increase early access: $74 \%$ of National Health Service (NHS)-funded abortions took place at under 10 weeks' gestation compared with $51 \%$ in 2002.

In $2009,94 \%$ of abortions were funded by the NHS; of these over half $(60 \%)$ took place in the independent sector under NHS contract. In $2002,78 \%$ of abortions were funded by the NHS; of these just over a third took place in the independent sector under NHS contract.

Ann Furedi, Chief Executive of the British Pregnancy Advisory Service (BPAS), said of the new statistics: "It's interesting to see that fewer abortions took place last year, for the second year running. We're really pleased that a greater proportion of abortions took place at the earliest stages in 2009 . There has been a $2 \%$ rise in the number of under 10 weeks' abortions, which now make up three quarters of all abortions. In fact $91 \%$ of all abortions were carried out at under 13 weeks of pregnancy. This probably indicates that better NHS funding has helped to build in more of the capacity needed to care for women when they need it. Unintended pregnancy and abortion will always be facts of life, because women wan to make sure the time is right for them to take on the important role of becoming a parent. Abortion statistics are reflective of women's very serious consideration regarding that significant role within their current situation."

\section{Source: www.dh.gov.uk}

\section{The Pleasure Principle}

FPA is offering a fresh new course for professionals called 'The Pleasure Principle', which explores how to carry out safe, educational work with young people around pleasure. Young people tell us, as part of their Sex and Relationships Education (SRE), they would like less factual information and more about forming positive partnerships and getting the most from an intimate relationship. The Pleasure Principle aims to explore how to support young people to have positive and enjoyable sexual relationships that can fit into conversations about risk and enable young people to feel more engaged with sexual health messages.

Professionals can expect discussions around promoting sex relationships, exploration into personal and professional attitudes to sexpositive work, exploration of sex-positive approaches to group work with young people, and communication about safer sex with young people in a sex-positive manner. For more details contact Helen Shipley (e-mail: Helens@fpa.org) or see the advertisement on page 184 of this issue.

\section{Mifepristone for intermenstrual bleeding with the LNG-IUS}

A group of researchers in New Delhi have studied the effects of mifepristone on intermenstrual bleeding in levonorgestrel-releasing intrauterine system (LNG-IUS) users. Thirty-six women using LNG-IUS for menorrhagia received $100 \mathrm{mg}$ mifepristone every 30 days for 3 months (Group 1). Fifty age-matched LNG-IUS users receiving no mifepristone were the control group (Group 2). At 3 months, median duration and episodes of intermenstrual bleeding/spotting were significantly lower in Group 1 compared with Group 2 ( 6 vs 12.5 days, $p=0.01 ; 2.5$ vs 3 , $p=0.05$, respectively). More women were satisfied with the LNG-IUS in the mifepristone group compared with the control group (75\% vs $44 \%, p=0.004)$. The effect was similar at 6 months. The researchers have concluded that mifepristone was effective in reducing the number of episodes and duration of intermenstrual bleeding/spotting in LNG-IUS users.

Reference

Lal S, Kriplani A, Kulshrestha V, Sharma M, Agarwal N. Efficacy of mifepristone in reducing intermenstrua vaginal bleeding in users of the levonorgestre intrauterine system. Int J Gynaecol Obstet 2010; 109 128-130.

\section{Social networking sites blamed for} increase in syphilis

Professor Peter Kelly, Director of Public Health for NHS Tees, said the biggest cause of spreading this serious disease was unprotected sex. He blames the use of social networking sites for casual sex on the four-fold rise in the number of cases of syphilis in heterosexuals in his area. More young women are being affected. In pregnancy syphilis can lead to miscarriage, stillbirth or disability. Professor Kelly warned people using the Internet to find sex to protect themselves. Symptoms depend on the development of the disease, and at first many sufferers are unaware of any problem. Nationally, the highest rates of syphilis are seen in women aged 20-24 years and men aged $25-34$ years. In 2008 there were 3588 cases of syphilis diagnosed in sexual health clinics across the UK.

Source: http://www.independent.co.uk/life-style/health-andfamilies/health-news/internet-casual-sex-is-blamed-for-r se-in-syphilis-1926371.html

Reviewed by Henrietta Hughes, MRCGP, DFSRH General Practitioner, London, UK 